\title{
Obstinação terapêutica sob o referencial bioético da vulnerabilidade na prática da enfermagem"
} Willfulness therapeutic under reference bioethical vulnerability the practice nursing

\author{
Cláudia D'Arco* \\ Luciane Lucio Pereira**
}

\section{Resumo}

\begin{abstract}
A tecnologia desencadeia dilemas bioéticos, entre eles a obstinação terapêutica. E frente a esses dilemas enfermeiros priorizam avanços tecnológicos aos saberes reflexivos. O objetivo da presente pesquisa foi o de compreender a percepção do enfermeiro de UTI sobre obstinação terapêutica, à luz do referencial bioético da vulnerabilidade. Como método, utilizou-se a pesquisa descritiva, análise do conteúdo de Bardin, com quatorze estudantes pós-graduandos do Curso de Especialização de uma instituição de ensino superior privada que atuavam em UTI, há mais de um ano, após aprovação do Comitê de Ética em Pesquisa e dos entrevistados. Como resultados obteve-se duas categorias: desconhecimento do conceito; posicionamento, com cinco subcategorias: passividade diante da decisão médica, dificuldade de enfrentar a terminalidade; percebendo negativamente a obstinação terapêutica, sentimentos em relação a terminalidade do jovem e criança, reconhecendo o papel do enfermeiro em relação a terminalidade. Desconhecimento sobre obstinação terapêutica influencia na vulnerabilidade do enfermeiro ao vivenciar tal situação, provavelmente não foi preparado durante a graduação e pós-graduação, principalmente quando os envolvidos são jovens ou crianças. Também estão despreparados a reconhecer quando a recuperação do paciente está em detrimento à tecnologia, necessitando consenso multiprofissional. Enfermeiros reconhecem a necessidade de controle da dor, diminuição do sofrimento e promoção da dignidade. Por fim, evidenciou-se a necessidade de inclusão dos aspectos bioéticos na formação do enfermeiro, pois identifica-se que estes não conhecem o conceito de obstinação terapêutica, porém reconhecem o prolongamento do processo de morte como negativo, principalmente quando estão envolvidos jovens, ainda sim, reconhecem seu papel na terminalidade. Preparar o enfermeiro desde a graduação, para lidar com situações de terminalidade possibilitará uma assistência de enfermagem mais adequada e com menor sofrimento dos envolvidos.
\end{abstract}

Palavras-chave: Assistência paliativa / ética. Papel do profissional de enfermagem. Unidade de Terapia Intensiva. Vulnerabilidade.

\begin{abstract}
The technology triggers bioethical dilemmas, including the therapeutic obstinacy, and face these dilemmas, nurses prioritize technological advances to reflective knowledge. The aim of this research was to understand the perception of the ICU nurse about therapeutic obstinacy in the light of bioethical term vulnerability. As a method, we used the descriptive research, analysis of Bardin content, with fourteen graduate students of the Specialization Course of a private institution of higher education who worked in the ICU for more than a year after approval by the Ethics Committee research and interviewed. As a result, there was obtained two categories: lack concept; positioning, with five subcategories: passivity in the face of medical decision, difficulty facing the terminal illness; negatively realizing the therapeutic obstinacy, feelings towards the terminally young child, recognizing the role of the nurse in relation to terminally. Ignorance of therapeutic obstinacy influences the vulnerability of nurses to experience such a situation probably was not prepared for the undergraduate and graduate levels, especially when those involved are young people or children. They are also unprepared to recognize when the patient's recovery is rather to technology, requiring multidisciplinary consensus. Nurses recognize the need for pain control, reduced suffering and promote dignity. Finally, evidence of the need for inclusion of bioethical issues in nursing education, it identifies that these do not know the concept of therapeutic obstinacy, but recognize the prolongation of the dying process as negative, especially when they are involved young, still yes, they recognize their role in terminally. Prepare the nurse since graduation, to handle terminal situations will enable a more adequate nursing care, with less suffering of those involved.
\end{abstract}

Keywords: Palliative care / ethics. Professional Nursing Role. Intensive Care Unit. Vulnerability .

DOI: $10.15343 / 0104-7809.20164003382389$

\#Artigo extraído da Dissertação de Mestrado apresentada ao Programa de Mestrado de Bioética do Centro Universitário São Camilo ${ }^{*}$ Centro Universitário São Camilo, São Paulo, SP, Brasil.

***Universidade de Santo Amaro. São Paulo, SP, Brasil

Os autores declaram não haver conflitos de interesse. 


\section{INTRODUÇÃO}

A Unidade de Terapia Intensiva (UTI) é o ambiente hospitalar em que o enfermeiro frequentemente enfrenta situações de obstinação terapêutica. É o lugar que tem como peculiaridade o atendimento a pacientes em estado grave e que necessitam de monitorização e vigilância constante de uma equipe multidisciplinar especializada ${ }^{(1)}$. Os profissionais que atuam nessas unidades têm conhecimento técnico científico apurado, devem acompanhar os avanços tecnológicos, o que os torna, por vezes, pouco reflexivos sobre os aspectos psicossociais envolvidos nessa assistência ${ }^{(2-3)}$.

O prolongamento da vida a qualquer custo, solidificou-se a medida que os avanços tecnológicos ocorreram, a partir do século XX. Assim, a prática da obstinação terapêutica tornou-se frequente nas UTIs. ${ }^{(4)}$. O emprego da tecnologia pode ser devastador para o doente, a partir do momento que esta é utilizada como instrumento de cura aos pacientes sem possibilidades terapêutica, transformando-se, em um recurso causador de sofrimento. Sem perspectivas de melhora, o doente é levado a padecer em decorrência da obstinação terapêutica ${ }^{(4)}$.

Em nosso meio, o termo obstinação terapêutica e distanásia, já há alguns anos tem sido alvo de debate e estudo nas obras de Pessini, sendo considerada como referência em outros Países ${ }^{(5,6)}$. O termo obstinação terapêutica e tratamento fútil não são citados nos dicionários. $O$ termo distanásia no dicionário Aurélio é conceituado como: "Morte lenta, dolorosa em consequência da agonia prolongada." ${ }^{\prime(7)}$. Considerada, também como a morte vagarosa, ansiosa e sofrida, decorrente de tratamentos desnecessários, ou fúteis, para manter o paciente vivo, por meio de medidas extraordinárias, geralmente caras, invasivas e tecnologicamente complexas ${ }^{(4)}$. Na concepção dos enfermeiros, essa prática relaciona-se como uma forma de morte cruel, com intensa dor e sofrimento, que, além de não beneficiar o paciente, provoca a recusa à morte e o afastamento da vida ${ }^{(5,6,8)}$.

A decisão de suspender ou manter o aparato tecnológico nos pacientes em processo de morte é uma conduta médica, porém o enfermeiro conhecendo a situação clínica, psicológica e o contexto familiar, cria um vínculo com o indivíduo doente e sua família. Assim, o enfermeiro torna-se o elo entre o paciente, a família e a equipe. Nesse contexto, o profissional enfermeiro será o responsável por promover uma assistência humanizada, prevenir a perda da dignidade na fase terminal e evitar a obstinação terapêutica ${ }^{(1,5,6)}$.

Os cuidados paliativos e a ortotanásia, surgem como uma opção de tratamento à obstinação terapêutica, possibilitando uma morte digna, sem abreviações, ou sofrimentos e procuram preservar a dignidade humana ${ }^{(7)}$. Os Cuidados paliativos promovem a qualidade de vida dos pacientes e familiares que enfrentam doenças ameaçadoras da vida, por meio da prevenção e alívio do sofrimento, avaliação correta e tratamento da dor e problemas de ordem física, psicossocial e espiritual ${ }^{(9)}$.

As situações práticas não podem ser analisadas apenas por meio da teoria principialista, que considera os princípios da autonomia, não-maleficência, beneficência e justiça durante o tratamento do paciente, pois frente a tomada de decisão de qual opção terapêutica seguir, seja a manutenção do tratamento curativo ou de medidas de conforto, além destes princípios ainda deve-se considerar o envolvimento dos profissionais da saúde, da família e do próprio paciente. Para tanto, a teoria dos referenciais fornece subsídios para uma análise e elaboração de questões éticas de modo mais preciso, propondo soluções mais adequadas e individualizadas. Utilizamos o referencial da vulnerabilidade para avaliar a posição do enfermeiro diante da obstinação terapêutica, já que na maioria das vezes, a decisão de manutenção de esforços é médica e o enfermeiro não se envolve nesta decisão, porém por estar inserido na assistência do paciente e família acaba realizando intervenções com as quais não concorda e passa de Ser vulnerável para uma situação de vulnerabilidade, desenvolvendo defesas instintivas e conscientes para garantir a sua integridade profissional e pessoal,

O termo "vulnerabilidade é de origem latina, derivando de vulnus (eis), que significa ferida, 
suscetibilidade do ser ferido. "(11).

As situações de obstinação terapêutica na Unidade de Terapia Intensiva, colocam a equipe multidisciplinar em situação de vulnerabilidade, o médico que dispõe de toda tecnologia para manutenção da vida precisa estabelecer o esgotamento das possibilidades terapêuticas para o paciente, decisão sofrida e solitária, na maioria das vezes tomada sem ser compartilhada com a equipe multidisciplinar. Este sofrimento que coloca o enfermeiro em situação de vulnerabilidade, está relacionado a questões culturais, emocionais e legais ou simplesmente por desconhecimento, por parte do médico ${ }^{(11)}$.

Neste contexto, o afastamento do profissional enfermeiro de tais situações, com carga emocional tão intensa, revela-se como mecanismo de defesa instintivo e inconsciente, os quais ele utiliza para afastar-se da condição de vulnerabilidade a qual será exposto no momento da decisão médica de manter a vida quando já foram esgotadas todas as medidas terapêuticas. Dor, sofrimento, enfrentado nos processos de morte e morrer dos pacientes, são provocados pelo despreparo e desconhecimento da situação de obstinação terapêutica, além da não participação da decisão para o prolongamento da vida do indivíduo ${ }^{(10)}$.

A "vulnerabilidade em bioética, apresentase como um desafio para a ação do sujeito autônomo diante de sujeitos vulneráveis" (11). O mundo tecnológico está fortemente marcado pelo poder e autonomia, e dificulta a percepção pelo homem dos seus limites e o reconhecimento de sua vulnerabilidade ${ }^{(12,13)}$.

Portando, considerando tal cenário, os objetivos deste estudo foram identificar o conhecimento de enfermeiras de UTI a respeito do conceito de obstinação terapêutica e distanásia, mediante o referencial bioético da vulnerabilidade, além de verificar como estes profissionais comportam-se e como reconhecem seu papel diante da obstinação terapêutica.

\section{MÉTODO}

Trata-se de uma pesquisa descritiva com abordagem qualitativa utilizando como referencial teórico a Análise de Conteúdo de Bardin. Conjunto de técnicas de análise das comunicações, que utiliza procedimentos sistemáticos e objetivos de descrição do conteúdo das mensagens por meio de 3 fases: pré-análise, exploração do material e tratamento dos resultados obtidos, construindo categorias e subcategorias, por meio da repetição dos elementos significativos que contextualizavam a mesma ideia.

Após autorização do Comitê de Ética e Pesquisa da Instituição, sob o protocolo de $n^{-}$149/09 e dos sujeitos da pesquisa, foram realizadas entrevistas individuais com gravação digital de dezembro de 2009 a fevereiro de 2010.

Participaram deste estudo 14 enfermeiras, alunas do curso de especialização do Centro Universitário São Camilo, que atuavam em UTI há mais de um ano na área. A escolha do local para a coleta de dados foi devido a instituição ser respeitada na formação de profissionais da área da saúde em nível de graduação e pósgraduação. Utilizou-se as questões norteadores baseadas em um caso clínico que possibilitou uma reflexão dos entrevistados sobre sua vivência diante da obstinação terapêutica.

Foram selecionados 25 alunos que possuíam as características utilizadas como critérios de inclusão no estudo, porém a repetição dos dados ocorreu a partir da $14^{\underline{a}}$ entrevista e garantiram a representatividade dos sujeitos.

Os depoimentos das entrevistadas foram identificados com a letra D de discurso, seguido do número da entrevista.

\section{RESULTADOS}

Obteve-se da análise do discurso, duas categorias e cinco subcategorias que segue: Desconhecimento do conceito de obstinação terapêutica e Posicionamento diante da terminalidade, está última, constituída por cinco subcategorias: passividade diante da decisão médica; dificuldade de enfrentar a terminalidade; percebendo negativamente a obstinação terapêutica; sentimentos em relação à terminalidade do jovem e reconhecendo o papel do enfermeiro em relação à terminalidade. 
Na categoria desconhecimento do conceito, as enfermeiras demonstram, em suas falas, o desconhecimento dos conceitos de distanásia e obstinação terapêutica, não sabiam defini-las e, quando o fizeram, acreditavam que eram termos diferentes, além de algumas vezes utilizá-los como sinônimos do termo eutanásia. O fato foi identificado nas falas

"Distanásia? ... Não. Obstinação terapêutica é esta questão de ficar investindo, investindo, investindo..., sem mesmo quando não tem prognóstico, né? Distanásia? ... Eu não sei. O que você pensa que é? Não, eu não sei o que é" (D4).

"Distanásia sim, Obstinação não. Distanásia é você prolongar também, né? Como vou te dizer? É uma vida mais, como vou te dizer, hummm....é o paciente não sofrer, não, não sofrer, ter uma morte digna, hummm... acho que é isso..." (D5).

O desconhecimento do conceito acaba por determinar um despreparo para identificar as situações de obstinação terapêutica, posicionar-se diante da equipe e a enfrentar situações nas quais o tema está envolvido. Estes aspectos, constituem a segunda categoria Posicionamento, que foi constituída por cinco subcategorias: passividade diante da decisão médica; dificuldade de enfrentar a terminalidade; percebendo negativamente a obstinação terapêutica; sentimentos em relação à terminalidade do jovem e reconhecendo o papel do enfermeiro em relação à terminalidade.

Na subcategoria, percebendo negativamente a obstinação terapêutica, observou-se o posicionamento contraditório nas falas destas enfermeiras entrevistadas, mas estas colocaramse contra o prolongamento do processo de morte.

"Eu acho, que a partir do quadro do paciente, que a partir do momento que não tem este prognóstico, que esta possibilidade de viver mais, eu acho que algumas medidas para prolongar como no caso da ventilação mecânica, no caso da diálise eu acho que é inviável? Você tem que deixar a pessoa morrer no tempo dela, mas sem estar prolongando". (D2)

$\mathrm{Na}$ subcategoria passividade diante da decisão médica existiu claro posicionamento das enfermeiras que a continuidade dos investimentos terapêuticos depende totalmente deste profissional. Essa dimensão aponta que, na maior parte das vezes, o papel do enfermeiro limita-se a cumprir o que está determinado, prescrito pelo médico, sem questionamento ou crítica. Por outro lado, os sujeitos da pesquisa, apontam a necessidade de preparo e diálogo para lidar com os vários aspectos envolvidos neste processo, não apenas técnico, mas também conhecimentos à respeitos das questões éticas e emocionais.

"Eu acho que a gente no dia a dia acaba fazendo, o que tem que ser feito, assim, o que é pedido, né? Pelo médico e não para muito para pensar no efeito que isso traria pro, pro.... doente, né? A gente vai, entra, acaba entrando na terapêutica, mesmo. Mas se gente for parar para pensar friamente né? Que...., Foge do nosso controle. Mas muitas vezes você fala, porque tudo isso. Se não vai levar há nada, né? Só ao sofrimento... Do paciente. Aqui acho que foge realmente do nosso controle, não é a gente que acaba comandando, né? A decisão não é nossa, não está em nossas mãos. A gente acaba, né? Cumprindo...O que é prescrito, O que.... É determinado, foge ao nosso controle, mas.... Não acho...que...isso leve a algum lugar, só ao sofrimento da pessoa e da família, né? " (D10)

Destacou-se nas falas das enfermeiras, na subcategoria dificuldade de enfrentar a terminalidade, a evidência de inabilidade para lidar com angústias dos familiares, da equipe e do paciente diante do sofrimento imposto pelo prolongamento do processo de morte.

Quando os questionamentos relativos à esperança e sofrimento se fazem mais presentes, bem como os limites do que a equipe pode fazer nesta situação, observou -se descrição de maior distanciamento entre as enfermeiras e a família.

"Já tive alguns neonatos que a gente sabia que não ia ter jeito. Ainda mais quando, é.... Que você vê..., que é incompatível, tudo que está acontecendo com a criança é incompatível com a vida, é difícil você ficar tendo o questionamento da mãe: " porque meu filho está sofrendo tanto? o que o bebê fez de tão grave para estar sendo punido deste jeito?(...) (D1)

É difícil para a família e até para o pessoal da equipe aceitar, né? Trabalhar com isso todo dia não é fácil..., quando a gente está lá com paciente que a gente conhece tudo, o sentimento que a gente não é Deus mesmo, não vai resolver, 
impotência...A complicação é quando o pessoal continua fazendo, querendo tudo que é possível mesmo que o paciente não melhore muito. " (D3)

Na subcategoria, sentimento em relação à terminalidade do jovem, revelou-se a maior dificuldade entre as entrevistadas em aceitar a situação de terminalidade em crianças, fato que as profissionais também observaram entre os familiares e demais membros da equipe multidisciplinar, e muito provavelmente são geradoras de situações de prolongamento do processo de morrer (obstinação terapêutica).

Esta posição do enfermeiro surge de valores e crenças determinados cultural e socialmente, os quais são transferidos para sua prática profissional, relacionados principalmente por ser considerados como a lei da vida, ou seja, os idosos devem morrer primeiro, e quando isso acontece parece ser menos doloroso para todos:

"(...) e eu acho que o fato de ser criança é pior ainda. Até buscar auxilio com psicologia, mas é muita dor..., é por que a família não espera, na verdade a lei da vida é que os mais velhos morram antes que os mais novos (...)" (D2)

Como última subcategoria obteve-se: reconhecendo o papel do enfermeiro na terminalidade, em que reconheceram como função primordial, o cuidado humano em momento difícil. Sabem que trazer o conforto é importante para amenizar o sofrimento, a dor do paciente e da família, e facilitar a aceitação da terminalidade. Acreditam que por meio de suas ações, proporcionam conforto, dignidade e compreensão da vida, estabelecendo um adequado processo de morte e morrer.

Para realizar esta função é necessário preparo, conhecimento sobre o tema, para assim conseguir elaborar uma argumentação consistente:

“(...) só que eu (enfermeiro) acho que ele está mais atento ao que o paciente está passando ou que a família está passando, dá apoio conversa muito com os familiares, mais apoio mesmo. (D3)

É o enfermeiro que tem mais contato com a família, do que a família que, do que a família gosta, gostaria que acontecesse com o ente querido deles. Às vezes, o médico tem a posição só mais de dar o tratamento, mais distante, então cabe a gente de fazer este vínculo entre a família e equipe médica de tal, dizendo o que eles gostariam de tal tentando respeitar e a maior parte das vezes, quando possível a decisão é dos familiares. " (D14)

\section{DISCUSSÃO}

Infere-se que o despreparo e o desconhecimento demonstrado pelas enfermeiras entrevistadas sobre o conceito de obstinação terapêutica e distanásia, ocorrem devido a formação profissional ser baseada em aspectos técnicos e práticos para a manutenção da cura dos pacientes e pouca ênfase é dada as questões emocionais e bioéticas ${ }^{(14)}$.

Essas profissionais agregam ao longo de suas vidas, crenças e valores fundamentados na sociedade ocidental, entre eles a sacralidade da vida, portanto as situações de morte são vistas por elas como fragilidade e fracasso ${ }^{(14)}$, além de apresentarem medo da morte, pois esta representa não só a extinção da espécie, mas a destruição do próprio corpo. Assim, ao defrontar-se com o processo de morte do paciente é obrigado a refletir sobre a sua própria morte $\mathrm{e}^{(15,16,17)}$.

Esta dificuldade de enfrentar no processo de morte e refletir sobre a sua destruição agrava-se quando o paciente, envolvido nesse processo, é jovem ou criança, pois nesse caso considerase como interrupção do ciclo biológico, provocando nos enfermeiros sentimentos que vão desde impotência, frustração, tristeza, dor, sofrimento e angústia; aspectos também identificados nas enfermeiras entrevistadas neste estudo ${ }^{(18)}$.

A categoria desconhecimento, influenciou também a categoria posicionamento e na maioria das subcategorias como, a passividade diante da decisão médica, dificuldade em aceitar a terminalidade e sentimentos em relação à terminalidade do jovem. Sentir-se despreparado para argumentar, assistir passivamente a decisão do médico e conscientemente acreditar que deste modo está diminuindo sua vulnerabilidade. Porém, diante disso, o enfermeiro é obrigado a realizar cuidados com os quais não concorda, e assumi uma postura 
defensiva que impede envolvimento e vínculo, causando assim, distanciamento dos pacientes e familiares que são atitudes contrárias à essência do seu exercício profissional $(10,11,19,20)$. Neste contexto, o enfermeiro torna-se um profissional suscetível a angústias e, deste modo, vulnerável. Esta vulnerabilidade, muitas vezes, se confirma por meio de doenças emocionais entre elas a Síndrome de Burnout, considerada a mais comum das doenças profissionais que conduzem ao afastamento do trabalho ${ }^{(10,11,21)}$.

Todo ser vivo ao vivenciar uma situação de vulnerabilidade reage instintivamente para proteger-se e garantir sua sobrevivência. As enfermeiras deste estudo, diante das situações de terminalidade, para evitar o sofrimento, o envolvimento emocional, afirmaram que buscam o afastamento do paciente e da família, sem ter a consciência que tal comportamento impede que o paciente tenha uma assistência humanizada compatível com a essência do seu exercício profissional ${ }^{(10)}$.

A definição da conduta, apesar de ser responsabilidade médica, também deve ser compartilhada com a equipe, visto que a assistência é realizada por diversos profissionais da área da saúde. A discussão e reflexões entre os profissionais que atuam em UTI e vivenciam a situação de obstinação terapêutica é enriquecedora, pois o diálogo estabelece comprometimento para promoção de uma assistência com maiores benefícios ao doente, sem desconsiderar a participação dos familiares neste processo. A participação dos enfermeiros, portanto é essencial, uma vez que ele trará para esta discussão a vontade do paciente e família ${ }^{(19-2)}$.

A passividade em relação às decisões médicas que o enfermeiro vivencia está marcada pela história, pois o berço da enfermagem deu-se no trabalho caritativo e voluntário das religiosas que prestavam cuidados aos doentes, trabalho este eminentemente feminino que mantém relação de submissão com a figura masculina desde o início da civilização, assim perpetua na assistência à saúde até os dias atuais, determinando e imprimindo sua marca diária nas relações estabelecidas entre médicos e enfermeiros ${ }^{(23)}$.

Nessa relação social que se estabelece entre médicos e enfermeiros, impõem-se a opressão imposta pela história e consequentemente a vulnerabilidade do enfermeiro com a diminuição da sua autonomia ${ }^{(12)}$.

O cuidado humanizado não impede a utilização de tecnologia, mas os profissionais que fazem uso dela devem estar preparados para aplicá-la, ou seja, esse profissional deve determinar o limite de sua utilização, que será definida individualmente para cada paciente após reflexão multidisciplinar realizada periodicamente. Quando os profissionais mantêm o controle do uso da tecnologia nas Unidades de Terapia Intensiva, promovem assistência centrada no ser humano, e, portanto, diminuem sua vulnerabilidade ${ }^{(24)}$.

Também deve-se refletir sobre como está o cuidado daqueles que cuidam, pois nas situações de vulnerabilidade e incapacidade estes adoecem emocionalmente, e consequentemente não estarão aptos a cuidar do outro, principalmente quando este outro está doente e em processo de morte e morrer (24).

Ao promover uma assistência que considera a vontade do paciente terminal, a equipe promoverá uma assistência humanizada e compatível com o princípio da beneficência, porém não poderá esquecer que existem limitações ao se definir o que significa o bem para os pacientes, principalmente para àqueles que estão internados na UTI, os quais as decisões são tomadas pelos profissionais da saúde, sem considerar, mesmo quando possível, a vontade do paciente ${ }^{(25)}$.

A preocupação com a dor, sofrimento e também com a dignidade não deve ser só dos pacientes, mas também de sua família. Tais aspectos, evidenciados por este estudo, além de ressaltar que ao cuidar do paciente grave é preciso ter em mente a importância da humanização no processo da assistência, pois aliviam e diminuem sentimentos desagradáveis no processo de morte e morrer.

Ao aceitar o cuidado, o paciente confia em quem cuida, e responde ao tratamento, demonstrando ter consciência da competência, responsabilidade e da atenção dispensada pelo profissional ${ }^{(9)}$.

Uma possibilidade de enfrentamento dessa vulnerabilidade, vivenciadas pelo enfermeiro está em prestar assistência ao 
paciente terminal, de acordo com a essência do cuidado proposto pela enfermagem por meio da filosofia dos cuidados paliativos. Nesta situação, o enfermeiro mantém sua autonomia e independência ao prestar a assistência, além da autonomia do paciente e da família ${ }^{(12)}$.

Os "cuidados paliativos" contrapõemse ao uso continuado, a qualquer preço, da tecnologia para a manutenção da vida em um paciente com doença incurável e avançada, ou seja, inviabiliza a "obstinação terapêutica". Portanto, parece ser uma opção de tratamento aos pacientes terminais que se compatibiliza com aquilo que as enfermeiras entrevistadas concordam, em ser uma assistência adequada, além do que esta prática de cuidados, não tem por meta abreviar a vida do paciente, surgindo como alternativa menos problemática moralmente para esses enfermeiros, os quais verbalizaram ser contra a eutanásia( ${ }^{(16)}$.

Esse tipo de abordagem do paciente terminal, também reconhece a interdisciplinaridade e concorda com a vontade do enfermeiro ao vivenciar as situações de obstinação terapêutica, diminuindo a sua vulnerabilidade, pois a discussão prévia ao cuidado está prevista nesta abordagem, além do cuidado humanizado focado na dignidade da vida.

Reconhecer que a sensibilidade é a vulnerabilidade própria da pessoa que o sensibilizou, permite que o enfermeiro admita o corpo vulnerável do paciente e, a partir dessa inquietação, o cuidado dispensado por esse profissional será um cuidado humanizado.

Esse cuidado humanizado, seguindo a filosofia dos cuidados paliativos, diminui as susceptibilidades dos profissionais que atuam em terapia intensiva, dentre eles o enfermeiro, os quais vivenciam situações de terminalidade evitando ou diminuindo sua vulnerabilidade, pois permite a autonomia de todos os envolvidos ${ }^{(10,12,24,25)}$.

\section{CONCLUSÂO}

Este estudo, fornece dados sobre o conhecimento dos enfermeiros sobre distanásia, tratamento fútil ou obstinação terapêutica e a vulnerabilidade destes profissionais diante de tal situação. Poderá contribuir para a elucidação desta problemática, além dos resultados possibilitarem discussões e reflexões sobre o tema que, apesar de muito prevalente nas Unidades de Terapias Intensivas, ainda é pouco conhecido pelos profissionais que atuam neste ambiente e principalmente pelo enfermeiro.

Identificou-se que o desconhecimento das enfermeiras entrevistadas sobre o tema, as coloca em situação de suscetibilidade e tornamse vulneráveis diante da situação de obstinação terapêutica, visto que este desconhecimento se demonstra no despreparo para lidar com a situação de terminalidade, pois gera sofrimento e angústia. Na tentativa consciente ou inconsciente de se protegerem, utilizam mecanismos de proteção, entre os quais o mais comum é o afastamento dos pacientes e suas famílias.

Esse afastamento do paciente e família, corrobora para a mecanização da assistência, valorização da técnica e afastamento destas enfermeiras da essência do seu exercício profissional que é o cuidar, portanto ao contrário do que se imagina, aumenta a sua vulnerabilidade.

O distanciamento das enfermeiras da essência da sua profissão, determinado pela inabilidade de reconhecer e lidar com as situações de terminalidade como a obstinação terapêutica, também promove sua dependência em relação as decisões médicas, demonstrada pelas enfermeiras entrevistadas na subcategoria passividade diante da decisão médica. Essa passividade e submissão marcada pela história da enfermagem, associada à ausência de argumentação, devido o desconhecimento sobre o tema, retiram a autonomia dessas enfermeiras e determinam a vulnerabilidade deste profissional.

Neste contexto, surge a necessidade de se repensar e reavaliar os conteúdos que estão sendo ministrados durante a graduação e pós-graduação, quanto à qualidade do ensino oferecida aos profissionais que estão sendo formados e encaminhados para o campo de trabalho. Parece necessário que recebam uma formação em relação aos aspectos éticos e bioéticos, os quais são relevantes para sua prática geral e específica de acordo com a sua especialização, mas objetivando a 
humanização, pois as enfermeiras da população estudada revelaram a necessidade de conhecer o que o paciente e a família gostariam que fosse realizado, mostrando que existe uma necessidade de colocar-se no lugar do outro.

Assim que as enfermeiras reconhecem a necessidade de cuidado humanizado nas situações de terminalidade como a obstinação terapêutica, estabelecem sua autonomia e buscam a atualização sobre o tema, pois percebem a necessidade de discutir com a equipe multidisciplinar.

Nessa assistência determinada pelo cuidado humanizado, reconhecem o limite da tecnologia, aproximam-se do paciente e da família, sendo o elo desses com a equipe e passam a ser os defensores da vontade dos mesmos, diminuindo novamente sua vulnerabilidade

\section{REFERÊNCIAS}

1. Bisogno SBC, Quintana AM, Camargo VP. Entre a vida enferma e a morte sadia: a ortotanásia na vivência de enfermeiros em unidade de terapia intensiva. Rev. Min. Enferm. 2010;14(3): 327-334.

2. Cavalheiro AM, Moura DF Jr, Lopes AC. Stress in nurses working in intensive care units. Rev Lat-am Enferm. 2008; 16(1):29-35.

3. Santana N, Fernandes JD. O processo de capacitação do enfermeiro intensivista. Rev Bras Enferm. 2008; 61(6):809-15.

4. Lima C. Medicina High Tech, obstinação terapêutica e distanásia. Soc Port Med Int. 2006; 13(2).

5.Pessini L. Distanasia: até quando investir sem agredir? Bioética, Brasilia, v 4, n1, p 31-43, 1996.

6. Passini L. Eutanasia: por que abreviar a vida? Loyola, São Paulo, 2004.

7. Baldessin A. Morrendo bem equipado. Med. 2005; 38(1):55-9.

8. Menezes MB, Selli L, Alves JS. Dysthanasia: nursing professionals' perception. Rev Latino-am Enfermagem. 2009;1 $7(4): 443-8$.

9. Waldow VR, Borges RF. O processo de cuidar sob a perspectiva da vulnerabilidade. Rev Lat-am Enferm.2008, jul/ago;16(4)

10. Hossne WS. Dos referenciais da bioética: a vulnerabilidade. Bioethikos. 2009 jan/jun; 3(1):41-51.

11. Neves MP. Sentidos da vulnerabilidade: característica, condição e princípio. Rev Bras Bioética. 2006; 2(2):157-172.

12. Anjos MF. A. vulnerabilidade como parceira da autonomia. Rev Bras Bioética. 2006; 2(2):173-85.

13. Gomes R. Desafios éticos do mundo técnico e tecnológico:entre recurso e vulnerabilidade. Bioethikos. 2010; 4(1):75-85.

14. Gutierrez BAO, Ciampone MHT. O processo de morte e morrer no enfoque dos profissionais de enfermagem da UTIs. Rev Esc Enferm USP. 2007; 41(4):660-7.

15. Bellato R, Carvalho EC. O jogo existencial e a ritualização da morte. Rev Lat-am Enferm. jan/fev; 13(1);99-104.

16. Bowlby J. Apego e perda. São Paulo: Martins Fontes; 1985. v. 3.

17. Kovács I. Como hacer visible el trabajo que el discurso dominante oculta. Sociol Trab Nueva Época. 2002; (45).

18. Spíndula T, Macedo MCS. A morte no hospital e seu significado para os profissionais. Rev Bras Enferm. 1994; 47(2):108-17.

19. Chaves AAB, Massarolo MCKB. Percepção de enfermeiros sobre dilemas éticos relacionados a pacientes terminais em Unidade de Terapia Intensiva, Rev Esc Enferm USP. 2009; 43(1):30-6.

20. Bermejo JC. Tradução de Guilherme Laurito Summa. Humanizar a saúde: cuidado, relações e valores. Rio de Janeiro: Vozes; 2008. 21. Meltzer LS, Huckabay LM. Critical care nurse' perceptions of futile care and its effect on burnout. Am J Crit Care. 2004; 13(3): 202-208.

22. Carvalho KK, Lunardi VL. Obstinação terapêutica como questão ética: enfermeiras de unidade de terapia intensiva. Rev Lat-am Enferm. $2009 ; 17(3): 308-13$.

23. Padilha MICS, Sobral VRS, Leite LMR, Peres MAA, Araujo AC. Enfermeira - a construção de um modelo de comportamento a partir dos discursos médicos do início do século. Rev. latino-am. Enfermagem. 1997; 5 (4): 25-33.

24. Girondi JBR et al. Risco,vulnerabilidade e incapacidade: reflexões com um grupo de enfermeiras. Rev Eletr Enferm. 2010; 12(2):207.

25. Barchifontaine CP. Problemas atuais de bioética. 8ª̣.ed. São Paulo: Centro Universitário São Camilo; 2001. 